\title{
ГОСУДАРСТВЕННО-ЧАСТНОЕ ПАРТНЕРСТВО И ФИНАНСИРОВАНИЕ РАЗВИТИЯ НАЦИОНАЛЬНОЙ ИНФРАСТРУКТУРЫ
}

\author{
(c) 2021 Ваславская Ирина Юрьевна \\ доктор экономических наук \\ Казанский (Приволжский) федеральный университет, Россия, Казань \\ E-mail:vaslavskaya@yandex.ru
}

В статье показана роль государственно-частного партнерства (ГЧП) как оптимального сочетания формальных институтов, представленных государственным сектором, и неформальных институтов, сформированных частным сектором. Анализ показал, что в настоящее время строительство и реструктуризация общественной инфраструктуры являются основополагающим фактором устойчивого роста национальной экономики. Показано, что, стабильные формальные институциональные условия для частных инвесторов, низкие транзакционные издержки, привлекательные финансовые параметры, могли бы обеспечить оптимальное соотношение бюджетного и частного финансирования государственных инфраструктурных ГЧП-проектов. Это позволит не только стабилизировать национальную бюджетную систему, но и обеспечить стабильный экономический рост в стране.

Ключевые слова: государственно-частное партнерство, формальные институты, проекты общественной инфраструктуры, дефицит бюджета, капитальные затраты бюджетных средств.

В современном мире важность новых подходов к адекватной институционализации взаимовыгодного партнерства между государством и частным бизнесом возрастает, поскольку темпы экономического развития почти всех стран земного шара замедляются, а национальные правительства демонстрируют неспособность переломить эту тенденцию. Во многом это связано с тем, что в последнее время произошли как количественные, так и качественные изменения в экономических функциях современных государств, которые не получили удовлетворительного теоретического объяснения [1], [2]. Например, остается открытым вопрос об оценке вклада государств в замедление роста национальных экономик. В то же время значительные доли (от 30 до 50\%) валового внутреннего продукта (ВВП) стран всего мира перераспределяются через систему государственных финансов [3]. Все вышесказанное позволяет нам сформулировать гипотезу о том, что государство способствует торможению развития национальных экономик из-за неэффективных государственных расходов в размере 1/3-1/2 ВВП, перераспределяемых в пользу государства.

Одним из эффективных механизмов обеспечения устойчивого экономического роста в мире становится развитие различных форм государственно-частного партнерства. Политики, ученые и практики согласились с тем, что к
2030 году достичь целей устойчивого развития (ЦУР) в мировой экономике можно будет только в том случае, если будет реализован огромный потенциал различных форм делового сотрудничества между государством и частным бизнесом. При этом, благодаря особой эффективности, на первое место были поставлены гибридные формы организации государственно-частного партнерства (ГЧП) в сфере долгосрочных капиталоемких и социально значимых инфраструктурных проектов. Фундаментальный смысл этого партнерства - объединение преимуществ организации сделок государством и частным бизнесом с целью минимизации экономических и финансовых потерь, характерных для каждого из них в отдельности.

Для оценки потенциала ГЧП в контексте необходимости обеспечения экономической и финансовой устойчивости чрезвычайно важными оказались научные разработки представителей институциональной теории, теории трансакционных издержек, экономической теории права и др. Эта фундаментальная теоретическая база позволила нам выделить три основные формы организации ГЧП [4] - квазирыночные, иерархические и гибридные. По нашему мнению, наиболее перспективными формами ГЧП являются гибридные организации партнерства государства и частного бизнеса при реализации инфраструктурных проектов, поскольку они обладают 
потенциалом ускорения экономического развития и обеспечения устойчивости государственных финансов. Это связано с тем, что государство всегда ограничено в расходах бюджета на капитальные проекты, но частные инвесторы могут быть привлечены для инвестирования в них на условиях, благоприятных для частных партнеров под патронатом государства. Учитывая вклад инфраструктуры в экономический рост, гибридные формы инфраструктурных проектов ГЧП можно с уверенностью отнести к наиболее перспективным в современных условиях бюджетной консолидации и замедления экономического роста в мире.

История развития ГЧП в национальных экономиках не так велика, поэтому на сегодняшний день остается много нерешенных вопросов, как теоретических, так и практических: какие факторы предопределяют разнообразие форм ГЧП, какие принципы следует считать основными при организации партнерства, от чего зависит эффективность механизмов финансирования ГЧП в различных областях государственного сектора, как можно оптимизировать интересы государственных и частных партнеров в различных моделях ГЧП, включая их гибридные формы И т.Д.

Множество нерешенных вопросов и отсутствие моделей наилучшего национального ГЧП практики объясняют ограниченным использованием потенциала различных форм государственно-частного партнерства в мировой экономике и отсутствием единого понимания их роли в стабилизации государственных финансов и обеспечении высоких темпов роста мировой экономики [4]. В связи с этим возникает очевидная необходимость теоретической интерпретации факторов разнообразия организационной структуры. партнерства (кооперации) государственного и частного секторов в экономической сфере, а также с выделения преимуществ каждой из их по отношению к разным сферам ответственности государства и с учетом фактора эффективного использования государства. бюджетные средства. Кроме того, это напрямую связано с проблемой всей мировой экономики, связанной с обеспечением ее высоких темпов роста в долгосрочной перспективе. Именно с этих позиций следует оценивать моделирование разнообразия потенциальных форм организации ГЧП с целью ускорения интеграции частного бизнеса в выполнение государ- ственных функций и обеспечения устойчивости государственных финансов.

На основе теоретических разработок представителей институционализма [5-8] можно структурировать три основные группы. организаций ГЧП - квазирыночные, иерархические и гибридные. Гибридные формы партнерства государства и частных инвесторов являются наиболее приемлемыми для развития социально значимой национальной инфраструктуры. По мнению экспертов, в перспективе до 2030 года именно инфраструктурные проекты ГЧП призваны служить ведущими драйверами экономического роста в мире [9]. С организационной точки зрения гибридные формы организации ГЧП чрезвычайно адаптивны, поскольку могут по соглашению партнеров сочетать наиболее приемлемые принципы сотрудничества между государственным и частным секторами, характерные для квазирыночных и иерархических базовых структур ГЧП. Кроме того, проектный подход к организации гибридных соглашений ГЧП оказался наиболее эффективным при реализации капиталоемких долгосрочных социально значимых инфраструктурных проектов. Это особенно важно в современных условиях замедления мировой экономической динамики, когда развитие инфраструктуры становится решающим фактором для долгосрочного экономического роста страны. Хорошо продуманные и эффективно осуществленные инвестиции в инфраструктуру могут способствовать экономическому развитию и улучшить доступ населения к основным услугам, повышающим качество жизни.

Потребность в инвестициях в инфраструктуру намного превышает их финансирование из традиционных источников, включая бюджетные средства. Проблема связана с тем фактом, что государственный сектор традиционно предоставлял основную часть инвестиций в инфраструктуру, учитывая присущий инфраструктурным проектам характер общественных благ. Но теперь государственные ресурсы в развитых, развивающихся странах и странах с развивающейся экономикой ограничены, поскольку правительства сталкиваются с растущей финансовой уязвимостью в результате бюджетного дефицита, более высоких отношений долга к ВВП, высоких процентных ставок, обесценивания валюты и увеличение бремени внешнего долга. В то же время финансирование от институтов раз- 
вития и донорских агентств вряд ли восполнит инфраструктурный пробел.

Хотя частный сектор часто рассматривается как «белый рыцарь» инфраструктуры, общий объем частных инвестиций в инфраструктуру в развивающихся странах только за период 19902018 гг. составил всего 1,6 триллиона долларов США в транспортном, энергетическом и водном секторах [10]. Это капля в море по сравнению с потребностями в инвестициях в инфраструктуру, которые составляют более 0,8 триллиона долларов США в год [11]. В этой связи нами предпринята попытка смоделировать возможные формы гибридных «институциональных матриц», объединив полномочия собственности и инструменты снижения трансакционных издержек (путем разделения рисков, разделения финансирования проектов ГЧП, условий покрытие затрат и доходность проекта), включая хорошо известные договоры концессии, управления и аренды; контракты на строительство, аренду и передачу и очень много неизвестных, но возможных «институциональных матриц».

Чем дальше, тем очевиднее становится, что перспектива решения проблем ускорения роста национальной экономики должна быть связана с масштабным прогрессом ГЧП в общественной инфраструктуре, который мог бы стать драйвером новейшей экономической истории. Успешные формы ГЧП в современном мире могут устранить временные кассовые разрывы национальных правительств, которые усугубляют их проблемы бюджетного дефицита в контексте общего замедления экономического роста. Для этих целей национальные правительства должны использовать бюджетные средства не столько для финансирования инфраструктурных проектов, сколько для создания соответствующих условий для частных инвесторов, включая институциональных игроков. Эти проблемы разрабатываются в наших исследованиях с целью управления устойчивым развитием национальной экономики с использованием взаимодействия государства и частных инвесторов в сфере общественной инфраструктуры, а также их организационной формы сотрудничества - ГЧП - в условиях принудительных фискальных ограничений и когда государственная инфраструктура может стать фундаментальным долгосрочным фактором развития национальной экономики.

Формализация модели замещения бюджетных средств частными инвестициями в пу- бличные инфраструктурные проекты, организованные в гибридной форме контрактов ГЧП, позволяет дать оценку положительного влияния консолидации государственных финансов на темпы роста национальной экономики с учетом следующих факторов:

1) специфики государства как делового партнера в сделках с общественными благами;

2) фактора минимизации транзакционных издержек как основы согласования интересов государства и частного бизнеса при выборе форм ГЧП;

3) обмена имущественными правами как функции изменения транзакционных издержек государственных и частных участников ГЧП;

4) основных форм институциональной организации государственно-частного партнерства.

Таким образом, с точки зрения устойчивости государственных финансов становится очевидным использование гибридных форм инфраструктурных проектов ГЧП для решения серьезной проблемы растущего бюджетного дефицита и увеличения стоимости обслуживания государственного долга во всем мире. В результате правительство должно использовать бюджетные средства для создания соответствующих условий для частных инвесторов, в том числе институциональных игроков, с целью расширения их участия в социальных проектах государства. Последнее означает, прежде всего, стабильные формальные институциональные условия для частных инвесторов, низкие транзакционные издержки, привлекательные финансовые параметры, которые могли бы довести соотношение бюджетного и частного финансирования инфраструктурных ГЧП-проектов более чем до 1:1.

Очевидно, что ускоренному развитию многих государственных инфраструктурных ГЧП-проектов препятствуют два фактора: недостаточная институциональная поддержка самого процесса проектирования и отсутствие подготовленных государством приемлемых финансовых моделей государственных инфраструктурных ГЧП-проектов в отношении разделения рисков инфраструктурных проектов и передачи прав собственности государства частным инвесторам. Плохое управление инфраструктурой остается ключевым камнем преткновения на пути к достижению целей в области устойчивого развития [12].

Являясь основой экономической производительности и взаимосвязанности стран, ин- 
фраструктура способствует многим действиям, необходимым для развития экономики. Хотя слабые места в системе управления различаются в зависимости от страны и политикоэкономического контекста, многим странам необходимо улучшить планирование проектов, лучше оценить доступность и усилить правила игры в правилах ГЧП своей инфраструктуры. В противном случае плохое управление и слабый потенциал могут привести к провалу проекта или реализации проектов слишком долго, что означает, что, либо инфраструктура не будет построена, либо правительство принимающей страны несет значительные дополнительные расходы из-за задержки проекта.

Устойчивая инфраструктура также должна быть «инклюзивной», а это означает, что она должна учитывать голоса всех граждан - богатых, бедных, мужчин и женщин - и обеспечивать их соответствие их потребностям, доступность и соответствие проектным спецификациям. Многие страны все чаще перекладывают ответственность за развитие, техническое обслуживание и финансирование инфраструктуры на государственные и местные органы власти. Это означает, что субнациональные учреждения должны развивать потенциал управления и планирования и, следовательно, кредитоспособность, чтобы привлекать финансирование для столь необходимой инфраструктуры. Моделирование результата замещения бюджетных средств частными инвестициями в публичные инфраструктурные проекты ГЧП позволяет нам оценить отрицательное и положительное влияние бюджетной консолидации на динамические характеристики экономических систем. При определенных условиях общественная инфраструктура может стать фундаментальным долгосрочным фактором национального экономического развития.

Проведенный анализ показал, что строительство и реструктуризация государственной инфраструктуры на основе гибридных контрактов ГЧП может стать основополагающим фактором ускоренного роста национальных экономик. В то же время часто возникает парадоксальная ситуация, связанная, с одной стороны, со значительным дефицитом хорошо структурированных публично подготовленных инфраструктурных проектов ГЧП, а с другой - с необходимым объемом частных инвестиционных ресурсов, потенциально готовых для финансирования таких проектов.
По словам создателей Global Infrastructure Outlook [9], потребности в глобальных инвестициях в инфраструктуру к 2040 году достигнут 94 триллионов долларов США, чтобы закрыть инфраструктурные пробелы из-за значительных экономических и демографических изменений. По оценкам McKinsey Global Institute, в период с настоящего момента до 2030 года потребуются инвестиции в инфраструктуру в размере 57 триллионов долларов - просто для того, чтобы не отставать от прогнозируемого роста мирового ВВП. Эта цифра включает в себя инвестиции в инфраструктуру, необходимую для транспорта (автомобильный, железнодорожный, порты и аэропорты), энергетики, водоснабжения и телекоммуникаций. По общему признанию, это приблизительная оценка, но ее масштаб значительный - почти на 60 процентов больше, чем 36 триллионов долларов, потраченных во всем мире на инфраструктуру за последние 18 лет. Требуемые инвестиции в размере 57 триллионов долларов превышают оценочную стоимость сегодняшней мировой инфраструктуры [13].Даже в этом случае этой суммы будет недостаточно для устранения серьезных отставаний и недостатков в обслуживании и обновлении инфраструктуры или для достижения более широких целей развития. стран с развивающейся экономикой. На этом фоне государственные ресурсы, вероятно, будут намного меньше того, что требуется для удовлетворения инвестиционных потребностей стран в области инфраструктуры.

Альтернативу финансирования инфраструктурных проектов за счет бюджетных средств автор связывает с привлечением в них частных инвестиций через организацию гибридных форм ГЧП. Гибридные контракты ГЧП могут привлекать частных инвесторов, используя такие стимулы, как, например, льготное налогообложение, стабильные условия ведения бизнеса на протяжении всего срока реализации инфраструктурного проекта ГЧП, заранее установленную норму возврата инвестиций. Иными словами, это связано не с ростом бюджетного финансирования, а с реализацией функции государства по эффективной институционализации внешней среды экономической деятельности частных партнеров гибридных проектов ГЧП. Умелое использование такого механизма позволило бы удвоить масштабы смешанных инвестиций в инфраструктурные проекты ГЧП, если бы доллар бюджетных средств мог привлечь 
доллар частных инвестиций. При этом можно добиться увеличения экономического эффекта в соответствии с арифметической прогрессией при увеличении притока частных инвестиций, привлеченных за счет бюджетных средств. Таким образом, гибридные формы организации ГЧП могут повысить эффективность капитальных затрат государственного бюджета и ускорить развитие общественной инфраструктуры как движущей силы экономического развития в ближайшем будущем. Более того, судя по результатам недавних исследований, практически все страны обладают огромным потенциалом частных инвестиций, которые можно было бы привлечь для финансирования долгосрочных инфраструктурных проектов ГЧП при условии получения адекватной прибыли. оценка с точки зрения частного партнера[14].Предлагаемый модельный подход к проблеме замещения средств государственного бюджета частными инвестициями в публичные инфраструктурные проекты ГЧП дает представление о новом подходе государства, позволяющем не только обеспечить устойчивость государственных финансов, но и стабилизировать национальную экономику в перспективе на 5-10 лет.

\section{Библиографический список}

1. Рuтmер, Герхард (1996). История социального государства (Рим: Laterza).Перевод из «Происхождение и развитие государства всеобеего благосостояния в международном сравнении» (Мюнхен: Р. Ольденбург Верлас, 1991)

2. Танц В., Шукнехт Л. (2000). Государственные расходы в 20-м веке: глобальная перспектива. Кембридж: Издательство Кембриджского университета.

3. Бюджетный монитор МВФ (октябрь 2018 г.). Управление общественным благосостоянием. Октябрь, Вашингтон, округ Колумбия: МВФ.

4. Ваславский Я., Ваславская И., (2019). Инфраструктурные проекты государственно-частного партнерства: политика бюджетной консолидации в России и повышение эффективности государственных расходов. В книге: Бруно С. Серджио (ред.) Моделирование экономического роста в современной России, Лондон: EmeraldPublishingLimited, PР. 199-228.

5. Ходжсон, Джеффри М. (2003). «Тайна рутины. Дарвиновская судьба эволюционной теории экономических изменений», Экономический обзор, Vol. 54, № 2, Марс, стр. 355-384

6. оуз Р.Х. (1972). «Промышленная организация: предложение для исследования». В: Виктор Фукс (ред.) Вопросы политики и возможности исследований в промышленных организациях. Том 3. Кембридж: NBER 59-73.

7. Уильямсон, О. (1996). Механизмы управления. Оксфорд: Издательство Оксфордского университета

8. Менар, К. (1997). Пилотирование гибридных организационных форм, Экономический обзор, 48 (2), PР.741751.

9. Обзор глобальной инфраструктуры (Global Infrastructure Outlook), (2018). Потребность в инвестициях в инфраструктуру в соглашении со странами Африки.Подготовлено OxfordEconomics для GlobalInfrastructureHub. Инициатива G20. Сидней: Центр глобальной инфраструктуры.

10. Всемирный банк, (2019) Глобальные экономические перспективы, январь 2019 г.: Вашингтон, округ Колумбия: Всемирный банк.

11. Руис-Нуньес, Фернанда; Вэй, Цзычао, (2015). «Потребности в инвестициях в инфраструктуру в странах с формирующимся рынком и развивающихся странах», Рабочий документ по анализу политики, № 7414, Вашингтон, округ Колумбия: Всемирный банк.

12. Всемирный экономический форум. (2019). Инклюзивный отчет о росте и развитии, 2019. Женева: ВЭФ.

13. Глобальный институт McKinsey, (2017). «Устранение пробелов в инфраструктуре. Достиг ли мир прогресса?» Документ для обсуждения в сотрудничестве с отделом капитальных проектов и инфраструктуры McKinsey. Октябрь. Вашингтон, округ Колумбия: McKinsey\&Company.

14. Арезки, Р.; П.Болтон; С. Петерс; Ф. Самама и Дж. Стиглиц.(2017).«От глобального избытка сбережений к финансовой инфраструктуре».Экономическая политика, том.32, вып. 90, стр.221-261 